\title{
Trends of Corneal Transplantation in Adults from 2010 to 2019 in East China: A 10-Year Experience
}

\author{
Songjiao Zhao ${ }^{a}$ Xichen Wan ${ }^{a}$ Wang Yao ${ }^{a}$ Jianjiang $\mathrm{Xu}^{\mathrm{a}}$ b Qihua Le ${ }^{\mathrm{a}, \mathrm{b}, \mathrm{c}}$ \\ aDepartment of Ophthalmology, Eye, Ear, Nose \& Throat Hospital of Fudan University, Shanghai, China; ${ }^{\text {b} M y o p i a ~ K e y ~}$ \\ Laboratory of Ministry of Health, Eye, Ear, Nose \& Throat Hospital of Fudan University, Shanghai, China; ${ }^{\circ}$ Research \\ Center, Eye, Ear, Nose \& Throat Hospital of Fudan University, Shanghai, China
}

\section{Keywords}

Keratoplasty · Indications · Surgical techniques · Eastern China

\begin{abstract}
Introduction: The aim of the study was to provide an overview of trends in the indications and surgical techniques for corneal transplantation in adults in East China from 2010 to 2019. Methods: The medical charts of all patients (aged $\geq 18$ years old) undergoing keratoplasty at the Eye, Ear, Nose and Throat Hospital of Fudan University between January 2010 and December 2019 were retrospectively reviewed. The indications for keratoplasty and the surgical techniques were collected. Results: A total of 2,929 cases were included. Acquired nontraumatic corneal diseases ( $n=1,927,65.8 \%$ ) have been the leading indication for corneal transplantation during the past decade. Although infectious keratitis was still the leading indication among acquired nontraumatic diseases, its absolute number and proportion gradually decreased during this decade $(p<0.001)$. In contrast, the proportion of endothelial dysfunction/bullous keratopathy increased from $7.8 \%$ in 2010 to $12.4 \%$ in 2019 ( $p=0.029$ ). Penetrating keratoplasty (PKP) has been the predominant
\end{abstract}

karger@karger.com www.karger.com/ore

Karger $\stackrel{\text { ' }}{5}$
(C) 2021 The Author(s)

Published by S. Karger AG, Basel

This is an Open Access article licensed under the Creative Commons Attribution-NonCommercial-4.0 International License (CC BY-NC) (http://www.karger.com/Services/OpenAccessLicense), applicable to the online version of the article only. Usage and distribution for commercial purposes requires written permission. surgical technique ( $n=1,854,63.3 \%)$, followed by deep anterior lamellar keratoplasty (DALK) $(n=361,12.3 \%)$ and endothelial keratoplasty (EK) ( $n=305,10.4 \%)$. Nevertheless, the proportion of PKP decreased from $77.6 \%$ in 2010 to $56.9 \%$ in 2019 ( $p=0.002)$ and was gradually replaced by DALK (from $7.8 \%$ to $16.3 \%, p<0.001$ ) and EK (from $3.4 \%$ to $10.4 \%, p=0.009)$. Conclusions: Over the past decade, infectious keratitis and endothelial dysfunction/bullous keratopathy have been the leading indications for keratoplasty in adults. Preferred surgical techniques for keratoplasty have been shifting from PKP to more customized lamellar keratoplasties.

(c) 2021 The Author(s).

Published by S. Karger AG, Basel

\section{Introduction}

The cornea is an indispensable component for maintaining normal vision. Corneal disorders are one of the leading causes of blindness worldwide and require corneal transplantation to restore vision [1]. However, indi-

Songjiao Zhao and Xichen Wan contributed equally to this work.
Correspondence to:

Qihua Le, qihuale_eent@163.com 
cations for corneal transplantation vary significantly by region. The leading indications for corneal transplantation in developed countries have been reported as pseudophakic bullous keratopathy, keratoconus, and Fuchs' endothelial dystrophy $[2,3]$. In contrast, the predominant indications in developing countries have remained infectious keratitis $[4,5]$ and keratoconus [6].

Since the first successful full-thickness corneal transplant by Zirm [7] in 1905, penetrating keratoplasty (PKP) has been the most commonly used technique in the treatment of various corneal disorders. However, the application of PKP is restricted due to the risk of graft rejection, the donor shortage, and other complications. In the past decade, various new surgical techniques for lamellar keratoplasty have been adopted and have gradually replaced PKP in clinical practice, including anterior lamellar keratoplasty (ALK), deep anterior lamellar keratoplasty (DALK), Descemet stripping endothelial keratoplasty (DSEK), Descemet membrane endothelial keratoplasty (DMEK), and keratolimbal allografting (KLA) [2, 8-12].

The most recent descriptive study focusing on the indications and techniques for corneal transplantation among adults ( $\geq 18$ years old) in China was published 10 years ago [4]. Regarding the donor shortage and the uneven distribution of medical resources in China, it is necessary to study shifts and trends over the recent decade to update the understanding of preoperative evaluation and surgical treatment. Therefore, we conducted this retrospective study to investigate the changing trends of indications and surgical techniques for keratoplasty in adults from 2010 to 2019 in East China.

\section{Materials and Methods}

The study conformed to the Declaration of Helsinki and was approved by the Ethics Committee of the Eye, Ear, Nose and Throat Hospital of Fudan University (approval number: 20150491). This is the largest tertiary eye care center in East China and the first eye center qualified to perform corneal transplantation in this area. The medical charts of adult patients ( $\geq 18$ years old) who underwent keratoplasty from January 1, 2010, to December 31, 2019, were reviewed. Demographic data, indications for corneal transplantation, surgical techniques, and other related information were collected and analyzed. All subjects have given their written informed consent to participate in the study.

Indications for corneal transplantation were divided into 4 categories: acquired nontraumatic corneal diseases, acquired traumatic corneal diseases, congenital corneal abnormalities, and regrafting. Each category covered various etiologies. Acquired nontraumatic diseases included infectious keratitis, keratoconus, endothelial dysfunction/bullous keratopathy, corneal degeneration, and noninfectious keratitis, such as neurotrophic and im-

Corneal Transplantation in East China mune keratitis. Bullous keratopathy caused by Fuchs' endothelial dystrophy (FED) was classified in this category, and these cases were not counted as congenital abnormalities to avoid duplication. Corneal opacity, staphyloma, and ulcers with an unknown cause were classified as unidentified in this category. Acquired traumatic diseases included mechanical, chemical, and thermal injuries. Congenital abnormalities included corneal dystrophy, congenital corneal opacity, and limbal dermoids. The regrafting category had the highest priority, which meant that if 1 eye had a history of corneal transplantation, it was classified as regrafting regardless of any other concomitant diagnoses or conditions.

The data are presented as the mean \pm SD. All data were analyzed with the Statistical Package for the Social Sciences (version 22.0; SPSS, Inc., Chicago, IL, USA). Pearson correlation coefficients and linear regression models were used to evaluate the trends of surgical techniques and main indications for corneal transplantation. $p$ values $<0.05$ were considered statistically significant.

\section{Results}

A total of 2,929 cases of keratoplasty (2,640 eyes) performed from 2010 to 2019 were included in the study. The mean age at the time of surgery was $48.3 \pm 16.4$ years (range: $18-90$ years). Men accounted for $66.5 \%$ of the cases.

\section{Indications}

Acquired Nontraumatic Corneal Diseases

Acquired nontraumatic corneal diseases were the leading indication for corneal transplantation $(n=1,927$, $65.8 \%)$ over the last 10 years. Infectious keratitis $(n=799$, $41.5 \%)$, endothelial dysfunction/bullous keratopathy $(n=$ $396,13.5 \%)$, and keratoconus $(n=348,10.8 \%)$ accounted for the majority of this category (shown in Table 1). Although infectious keratitis remained the leading etiology among all acquired nontraumatic corneal diseases, its proportion decreased gradually from $47.8 \%$ in 2010 to $30.4 \%$ in $2019(p<0.001)$ (shown in Fig. 1a). Fungus was the most common pathogen in infectious keratitis, showing a relatively stable trend $(p=0.729)$ during this decade. In contrast, endothelial dysfunction/bullous keratopathy showed a significant increasing trend from $7.8 \%$ in 2010 to $12.4 \%$ in 2019 ( $p=0.029$, shown in Fig. $1 \mathrm{~b}$ ), half of which was caused by intraocular surgeries, including cataract surgery $(n=158,39.9 \%)$ and combined surgeries $(n=91,23.0 \%)$ (shown in Fig. 2). The proportion of KC did not significantly change $(p=0.152)$ (shown in Fig. 1c).

\section{Acquired Traumatic Corneal Diseases}

Acquired traumatic corneal diseases $(n=349)$ accounted for $13.5 \%$ of all cases (shown in Table 1). Its pro- 


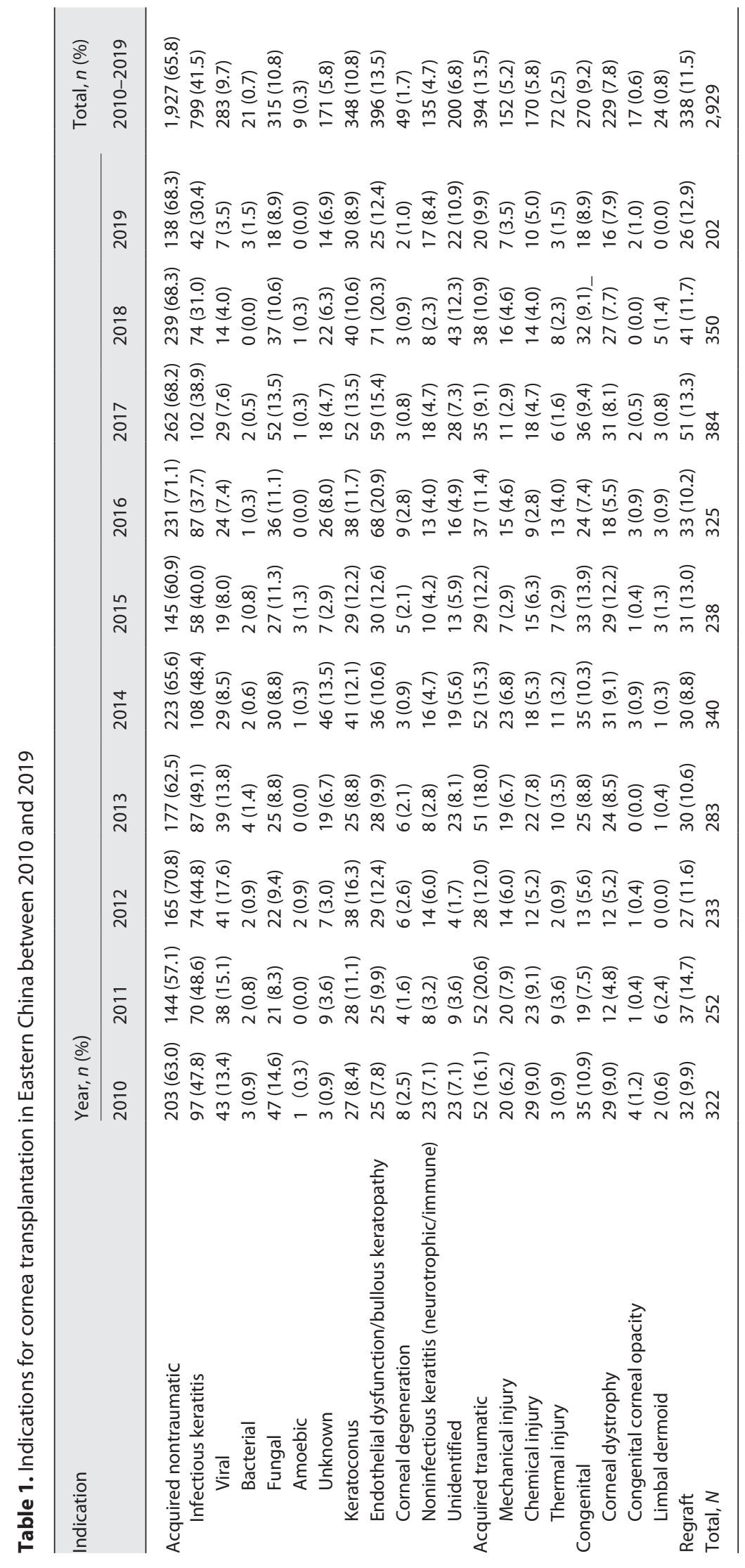




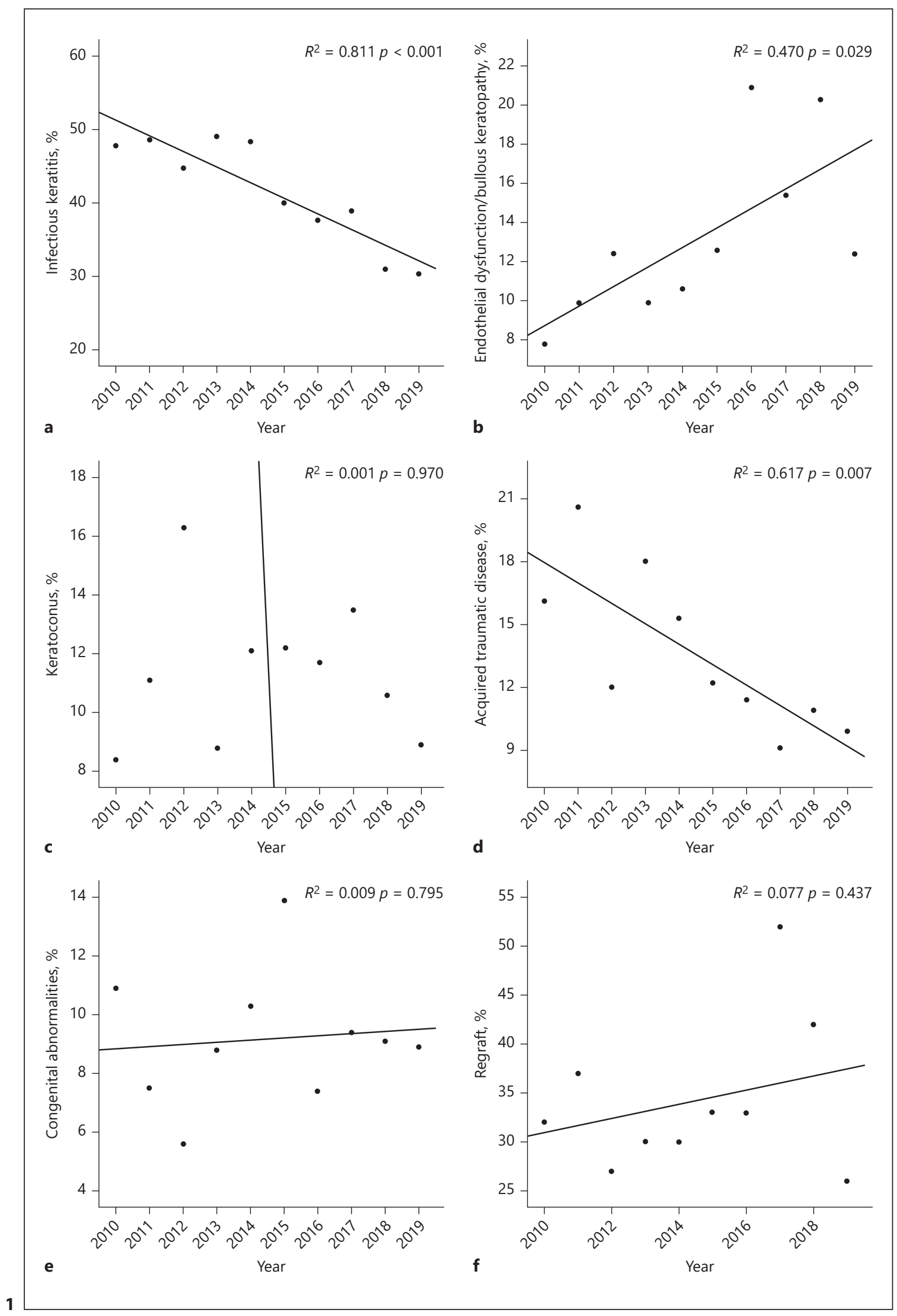

(For legend see next page.) 
portion decreased significantly over the past 10 years ( $p=0.007$, shown in Fig. $1 \mathrm{~d}$ ). The most common indication of this category was chemical injury $(n=170,48.7 \%)$, followed by mechanical injury $(n=152,43.6 \%)$. Males accounted for the majority $(n=335,81.1 \%)$ of the recipients in this category.

\section{Congenital Corneal Abnormalities and Regrafting}

Congenital corneal abnormalities $(n=270)$ accounted for $9.2 \%$ of the total cases (shown in Table 1). The propor-

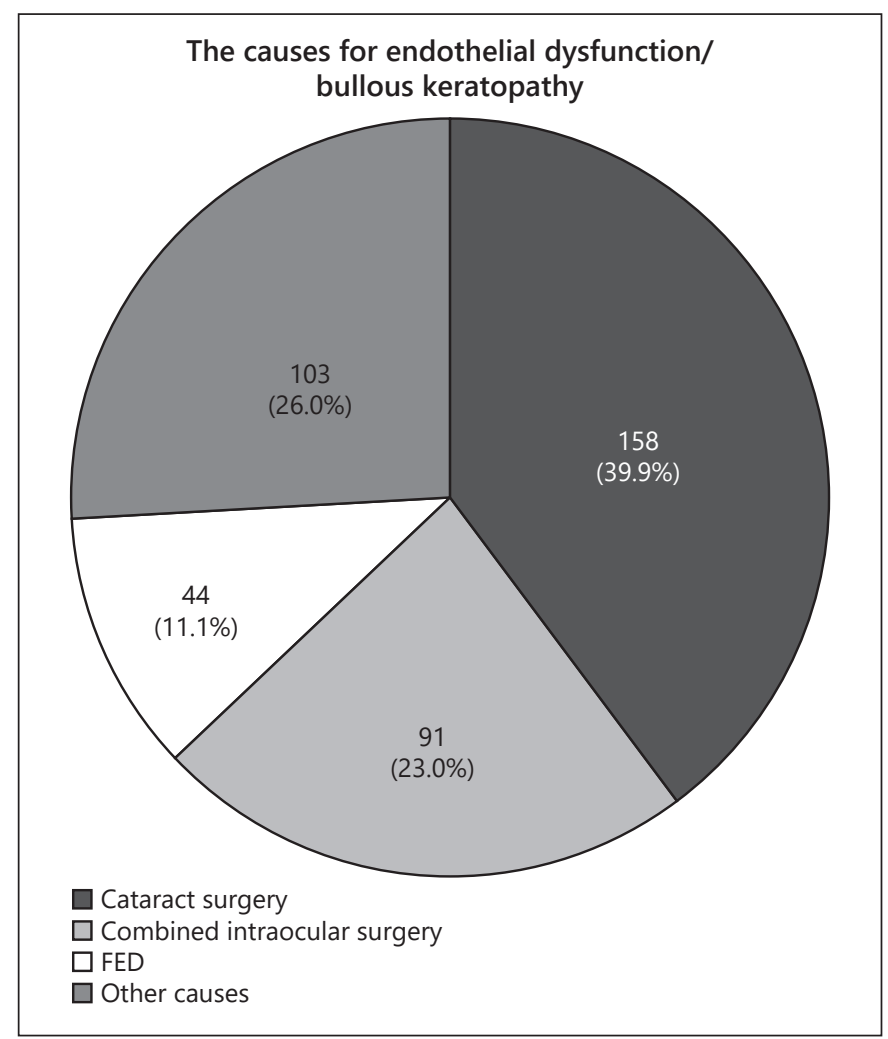

Fig. 2. The causes for endothelial dysfunction/bullous keratopathy from year 2010 to 2019. Cataract surgery remained the leading cause for endothelial dysfunction/bullous keratopathy (39.9\%), followed by combined surgery (23.0\%) and FED (11.1\%). FED, Fuchs' endothelial dystrophy.

Fig. 1. Changing trend of main indications for corneal transplantation from year 2010 to 2019. Both infectious keratitis (a) and acquired traumatic disease $(\mathbf{d})$ showed a significant decreasing trend ( $p<0.001$ and $p=0.007$, respectively). Endothelial dysfunction/ bullous keratopathy $(\mathbf{b})$ showed a significant increasing trend $(p=$ 0.029 ). Keratoconus (c) and congenital abnormalities (e) maintained a stable proportion within the recent decade $(p=0.970$ and $p=0.795$, respectively). Regraft (f) had no significant changing trend in this decade, too $(p=0.473)$. tion of congenital corneal abnormalities revealed no significant change during this decade $(p=0.795$, shown in Fig. 1e). Regrafts $(n=338)$ accounted for $11.5 \%$ of the total cases (shown in Table 1) and showed no significant trend of change in this decade ( $p=0.473$, shown in Fig. 1f).

\section{Age Distribution of Indications}

According to the age, all subjects were divided into 3 groups: $18-40$-year-old group $(n=981), 41-60$-year-old group $(n=1,171)$, and $>60$-year-old group $(n=777)$. The distribution of the indications among 3 groups was compared (shown in Table 2). Keratoconus was the leading indication in 18-40-year-old group ( $n=330,33.6 \%)$. Nevertheless, infectious keratitis was the primary indication for keratoplasty in both 41-60-year-old group ( $n=$ $392,33.5 \%)$ and $>60$-year-old group $(n=271,34.9 \%)$. The proportion of acquired traumatic and congenital disorder was significantly lower in $>60$-year-old group than in the other 2 groups $(p=0.001$ and $p=0.001)$.

\section{Surgical Technique}

PKP has been the most common technique for keratoplasty $(n=1,854,63.3 \%)$ during the past decade, followed by DALK $(n=361,12.3 \%)$, endothelial keratoplasty (EK) with both DSEK and DMEK included $(n=305,10.4 \%)$, $\operatorname{ALK}(n=238,8.1 \%)$, and KLA $(n=168,5.7 \%)$ (shown in Fig. 3a, b). Nevertheless, the proportion of PKP decreased from $77.6 \%$ in 2010 to $56.9 \%$ in 2019 ( $p=0.002$, shown in Fig. 3b). In contrast, EK and DALK showed a significant increasing trend from $3.4 \%$ and $7.8 \%$ in 2010 to $10.4 \%$ and $16.3 \%$ in 2019 , respectively $(p<0.001$ and $p=0.009$, shown in Fig. 3b). KLA showed no trend of change in this decade ( $p=0.055$, shown in Fig. $3 b$ ).

Infectious keratitis was the most common indication ( $n=686,36.94 \%)$ for PKP in the past decade. Nevertheless, its proportion decreased from $93.8 \%$ in 2010 to $76.2 \%$ in 2019 ( $p=0.001)$. DALK has replaced PKP and become the main technique for treating keratoconus in the last 10 years, with its proportion dramatically increasing from $14.8 \%$ in 2010 to $60.0 \%$ in $2019(p<0.001)$ (shown in Fig. 3c). Acquired traumatic corneal diseases were the leading indication for KLA $(n=53,37.3 \%)$ and $\operatorname{ALK}(n=$ $52,28.0 \%)$. Regarding the surgical technique for endothelial dysfunction/bullous keratopathy, a change was found over the past 10 years, which was characterized by a significant reduction in PKP $(p=0.001)$ and a gradual increasing trend in DSEK $(p=0.019)$ and $\operatorname{DMEK}(p=0.005)$ (shown in Fig. 3d). 
Table 2. Distribution of the indications for cornea transplantation of each age group

\begin{tabular}{|c|c|c|c|c|}
\hline Indications & $18-40$ & $41-60$ & $>60$ & $p$ value* \\
\hline Acquired nontraumatic & $623(63.5)$ & $720(61.5)$ & $584(75.2)$ & $<0.001$ \\
\hline Infectious keratitis & $136(13.9)$ & $392(33.5)$ & $271(34.9)$ & $<0.001$ \\
\hline Viral & $53(5.4)$ & $147(12.6)$ & $83(10.8)$ & $<0.001$ \\
\hline Amoebic & $2(0.2)$ & $3(0.3)$ & $4(0.5)$ & 0.358 \\
\hline Unknown & $43(4.4)$ & $65(5.6)$ & $63(8.1)$ & 0.004 \\
\hline Keratoconus & $330(33.6)$ & $16(1.4)$ & $2(0.3)$ & $<0.001$ \\
\hline Endothelial dysfunction/bullous keratopathy & $62(6.3)$ & $143(12.2)$ & $191(24.6)$ & $<0.001$ \\
\hline Corneal degeneration & $12(1.2)$ & $24(2.0)$ & $13(1.7)$ & 0.330 \\
\hline Noninfectious keratitis (neurotrophic/immune) & $28(2.9)$ & $67(5.7)$ & $40(5.1)$ & 0.005 \\
\hline Chemical injury & $78(8.0)$ & $80(6.8)$ & $12(1.5)$ & $<0.001$ \\
\hline Thermal injury & $27(29.7)$ & $41(3.5)$ & $4(0.5)$ & $<0.001$ \\
\hline Congenital & $115(11.7)$ & $104(8.9)$ & $51(6.6)$ & 0.001 \\
\hline Corneal dystrophy & $83(8.5)$ & $96(8.2)$ & $50(6.4)$ & $<0.001$ \\
\hline Congenital corneal opacity & $9(0.9)$ & $7(0.6)$ & $1(0.1)$ & 0.096 \\
\hline Limbal dermoid & $23(2.3)$ & $1(0.1)$ & $0(0.0)$ & $<0.001$ \\
\hline Regraft & $98(10.0)$ & $145(12.4)$ & $95(12.2)$ & 0.175 \\
\hline
\end{tabular}

${ }^{*} \mathrm{X}^{2}$ test among 18-40-year-old group, 41-60-year-old group, and $>60$-year-old group.

\section{Eye Bank Practice}

According to the records of donors from the eye bank affiliated to Shanghai Red Cross Society, a total of 4,244 donors were collected from 2010 to 2019. The annual number of donor tissue increased from 336 in 2010 to 567 in 2017, which was highly consistent with the changing trend of keratoplasty cases during this decade $(R=0.689$, $p=0.028$ ) (shown in Fig. 3e). The proportion of endothelial grafts had a significant increasing trend from $2.1 \%$ in 2010 to $11.8 \%$ in 2018 ( $p=0.033$ ) (shown in Fig. 4a). Notably, all endothelial grafts were prepared using microkeratome from 2010 to 2015 . However, femtosecond laser has been cautiously applied in the preparation of corneal endothelial grafts since 2016 (shown in Fig. 4b).

\section{Discussion}

The total number of keratoplasties per year in the last decade was remarkably higher than that reported from 1994 to 2010 in East China $[4,13]$. The development of customized lamellar keratoplasty due to the advancement of surgical techniques was the major reason, as these advancements made it possible to transplant 1 donor cornea to 2 or even more recipients. Socioeconomic improvements and popularization of the concept of organ donation are also contributing factors. The current study confirmed an increasing annual number of donor cornea in the past decade. However, the annual number of keratoplasties is far less than that reported in developed countries $[2,14,15]$. The donor shortage is still the major restricting factor in China.

The annual number of PKP procedures in the last decade was 7.8 times higher than that reported from 1994 to 2003 [14]. However, the proportion of PKP has been decreasing steadily, and this procedure has been gradually replaced by lamellar keratoplasty procedures, such as EK and DALK. Moreover, in the last decade, the average number and proportion of PKP procedures performed to treat infectious keratitis, the leading indication for keratoplasty in middle-aged and old Chinese people, showed a nearly $40 \%$ reduction compared with those reported 15 years ago [4]. There are several possible reasons for this trend. Innovations in agricultural automatization and protection have 


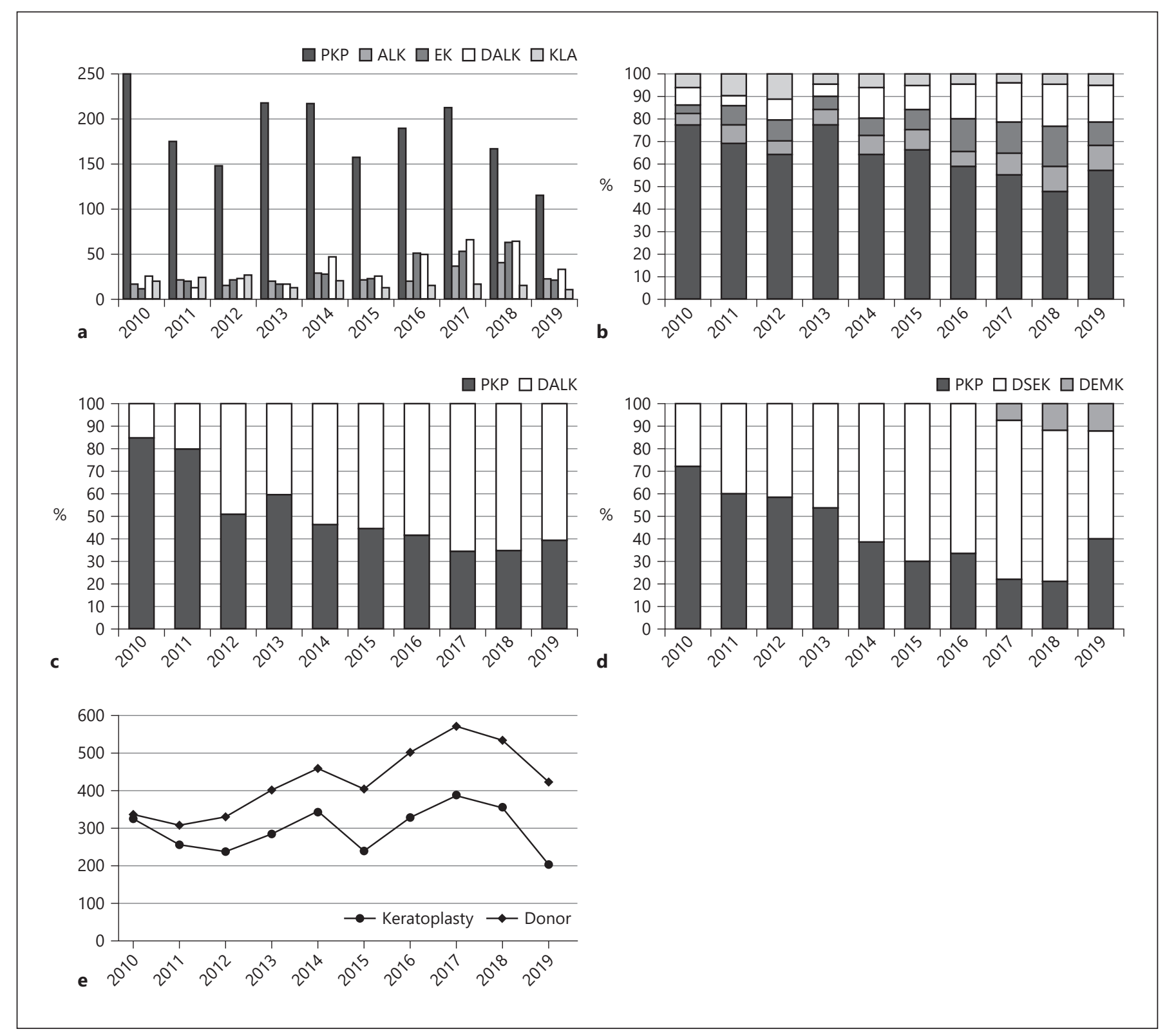

Fig. 3. Changing trend of each surgical technique and the number of donor tissues from year 2010 to 2019 . The absolute number per year of PKP (a) and its proportion (b) decreased significantly from 2010 to 2019 ( $p=0.002$ ), whereas the proportion of ALK, DALK, and EK showed a significant increasing trend $(p=0.009, p<0.001$ and $p=0.009$, respectively). No significant changes were found concerning KLA $(p=0.055)$. Shifts of surgical technique for keratoconus (c) showed that DALK replaced PKP and became the main technique to treat keratoconus $(p<0.001)$. The proportion of PKP to treat endothelial dysfunction/bullous keratopathy (d) has been decreasing over the past 10 years $(p=0.001)$. Meanwhile, the pro-

portion of DSEK and DMEK showed a significant rising trend ( $p$ $=0.019$ and $p=0.005)$. e Regardless of the age of the recipients, the total number of donors from 2010 to 2019 was 4,244. The changing trend of the number of keratoplasty cases per year was highly consistent with the annual number of donor tissues during this decade $(R=0.689, p=0.028)$. PKP, penetrating keratoplasty; ALK, anterior lamellar keratoplasty; DALK, deep anterior lamellar keratoplasty; EK, endothelial keratoplasty; KLA, keratolimbal allografting; DSEK, Descemet stripping endothelial keratoplasty; DMEK, Descemet membrane endothelial keratoplasty. 


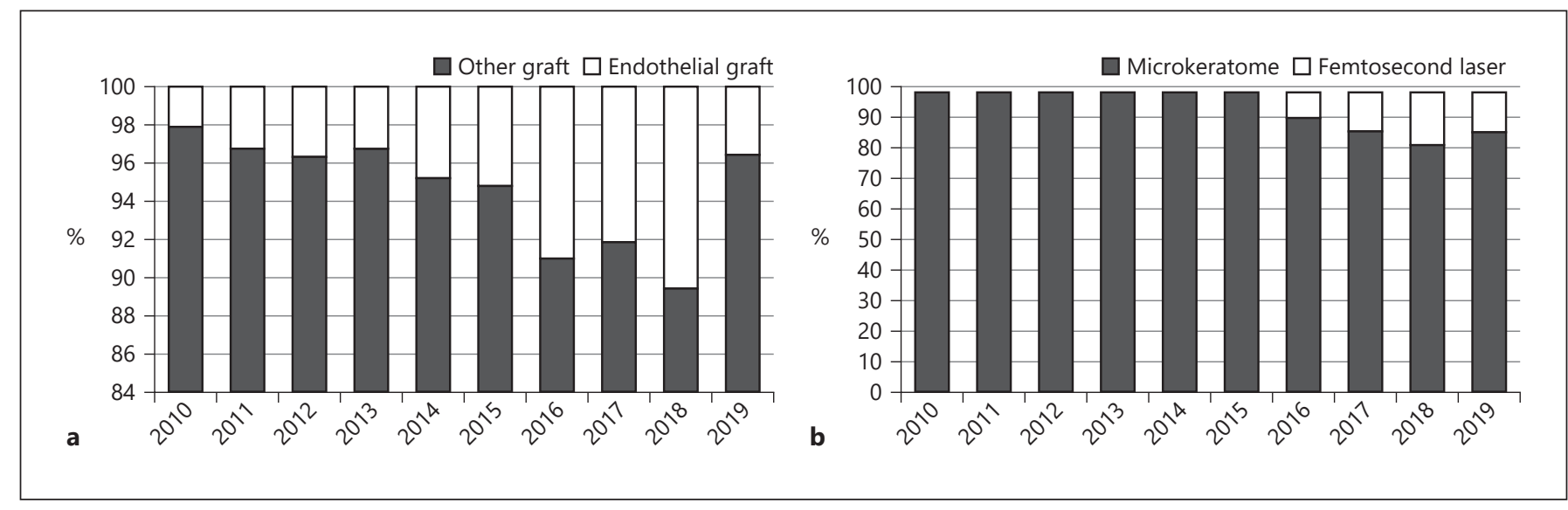

Fig. 4. Changing trend of endothelial grafts from year 2010 to 2019. The proportion of endothelial grafts (a) increased significantly from 2010 to 2019 ( $p=0.033$ ). The endothelial grafts $(\mathbf{b})$ were all prepared with microkeratome from 2010 to 2015 . Femtosecond laser has been applied in the preparation of corneal endothelial grafts since 2016, but its proportion is quite low.

reduced the risk of fungal infection, which was confirmed by our finding that the annual number of infectious keratitis decreased in the recent decade. Improved diagnostic techniques, such as confocal microscopy and polymerase chain reaction, have facilitated the early and accurate diagnosis of infectious keratitis, reducing the number of severe cases requiring PKP $[16,17]$. ALK, DALK, and even new options, such as collagen cross-linking, might replace PKP in some early cases [18-20].

Unlike in the USA, in East China, the leading cause of endothelial dysfunction/bullous keratopathy during the past decade was cataract surgery rather than FED [2]. Our finding is in agreement with those of previous studies [4, 13]. The dramatically increasing demand for cataract surgery due to the aging population in China and the uneven distribution of medical resources, especially experienced surgeons, are possible reasons. EK has been introduced in clinical practice to treat bullous keratopathy since Melles et al. [21] reported this surgical technique in 1998. It involved a smaller incision, a lower rate of induced astigmatism, and faster and better visual recovery than PKP. Even with technical challenges, its clinical application has been dramatically increasing in the past decade, with surgical procedures transitioning from deep lamellar endothelial keratoplasty to DSEK and further to DMEK [22]. Our study confirms this trend. However, the annual number of DMEK procedures is lower in the current study than other studies in developed countries [12]. The shortage of high-quality donor corneas restricts the clinical application of these procedures in China.

Corneal Transplantation in East China
A significant increasing trend in DALK procedures was noted in the current study, half of which were performed for the treatment of keratoconus, the leading indication for keratoplasty in 18-40-year-old subjects. With the advantages of similar visual outcomes and less risk of endothelial dysfunction, rejection, and other longterm complications, DALK has replaced PKP and has become the main technique for the treatment of keratoconus. Moreover, its application has been gradually expanded to treat infectious keratitis and corneal leukoma without endothelial involvement in the last decade $[2,3$, 23 ], which is in agreement with the findings of the present study.

KLA accounted for only $5.8 \%$ of keratoplasty procedures in the current study, and its proportion and absolute number have decreased significantly in recent years. Unlike in infants and toddlers [24], in adults, KLA is mainly performed to treat limbal stem cell deficiency caused by chemical or thermal injury. Nevertheless, the long-term outcome of KLA is not satisfactory [25]. With the rapid development of stem cell therapy, KLA has been gradually replaced by ex vivo cultivated limbal epithelial transplantation [26] and simple limbal epithelial transplantation $[27,28]$.

Admittedly, Chinese ophthalmologists have to face a formidable challenge, the low availability of donor c orneas, and it might continue for a long time. Moreover, many corneas from elderly donors are not suitable for PKP or EK because of low endothelial cell counts or other age-related pathological changes. Therefore, the 
popularization of customized lamellar keratoplasty and the development of cell therapies [29] or other alternative corneal equivalents $[30,31]$ are urgently needed.

The current study has several limitations. First, this was a retrospective study based on inpatients' medical records. Follow-up data such as the final outcome of graft and postoperative visual acuity after discharge from the hospital were not available. Second, this was a single-center study. Selection bias might not be avoidable. Hence, multicenter, large-scale prospective studies are needed to explore the causal relationships among indications, surgical methods, outcomes, and prognosis.

\section{Conclusion}

Infectious keratitis and endothelial dysfunction have remained the most common indications for keratoplasty in China in the last decade. PKP has been gradually replaced by customized lamellar keratoplasty in clinical application. Regarding the donor shortage in China, which might not be alleviated in the short term, it is necessary to popularize lamellar keratoplasty and develop cell therapies or other alternative therapies.

\section{Acknowledgments}

The authors thank Wang Yao and Xiaoyan Li for their help in data collection. Wang Yao and Xiaoyan Li agreed with their names appearing in the manuscript in case of publication.

\section{Statement of Ethics}

The study was conducted ethically in accordance with the World Medical Association Declaration of Helsinki. This study protocol was reviewed and approved by the Ethics Committee of the Eye, Ear, Nose and Throat Hospital of Fudan University, approval number [2015049-1]. All subjects have given their written informed consent to participate in the study.

\section{Conflict of Interest Statement}

The authors declare that they have no competing interests.

\section{Funding Sources}

The collection, analysis, and interpretation of data in this study were supported by the National Natural Science Foundation of China (NSFC) (81970767) and the Natural Science Foundation of Shanghai (SCST) (19ZR1408200).

\section{Author Contributions}

Songjiao Zhao analyzed and interpreted the patient data and was a major contributor in writing the manuscript. Xichen Wan and Wang Yao contributed to data collection. Jianjiang Xu supported in study design, data collection, and draft writing. Qiahua Le supported in study design, draft writing, and revising. All authors read and approved the final manuscript.

\section{Data Availability Statement}

The datasets used and/or analyzed during the current study are available from the corresponding author on reasonable request.

\section{References}

1 Tran TM, Duong H, Bonnet C, Kashanchi A, Buckshey A, Aldave AJ. Corneal blindness in Asia: a systematic review and meta-analysis to identify challenges and opportunities. Cornea. 2020;39(9):1196-205.

2 Park CY, Lee JK, Gore PK, Lim CY, Chuck RS. Keratoplasty in the United States: a 10-year review from 2005 through 2014. Ophthalmology. 2015;122(12):2432-42.

3 de Sanctis U, Alovisi C, Bauchiero L, Caramello G, Girotto G, Panico C, et al. Changing trends in corneal graft surgery: a ten-year review. Int J Ophthalmol. 2016;9(1):48-52.

4 Wang JY, Xie LX, Song XS, Zhao J. Trends in the indications for penetrating keratoplasty in Shandong, 2005-2010. Int J Ophthalmol. 2011;4(5):492-7.
5 Sony P, Sharma N, Sen S, Vajpayee RB. Indications of penetrating keratoplasty in Northern India. Cornea. 2005;24(8):989-91.

6 Rezaei Kanavi M, Javadi MA, Motevasseli T, Chamani T, Rezaei Kanavi M, Kheiri B, et al. Trends in indications and techniques of corneal transplantation in Iran from 2006 to 2013; an 8-year review. J Ophthalmic Vis Res. 2016;11(2):146-52.

7 Zirm EK. Eine erfolgreiche totale keratoplastik (a successful total keratoplasty). 1906. Refract Corneal Surg. 1989;5(4):258-61.

8 Boynton GE, Woodward MA. Evolving techniques in corneal transplantation. Curr Surg Rep. 2015;3(2).
9 Frigo AC, Fasolo A, Capuzzo C, Fornea M Bellucci R, Busin M, et al. Corneal transplantation activity over 7 years: changing trends for indications, patient demographics and surgical techniques from the corneal transplant epidemiological study (CORTES). Transplant Proc. 2015;47(2):528-35.

10 Woo JH, Ang M, Htoon HM, Tan D. Descemet membrane endothelial keratoplasty versus descemet stripping automated endothelial keratoplasty and penetrating keratoplasty. Am J Ophthalmol. 2019;207:288-303.

11 Singh A, Zarei-Ghanavati M, Avadhanam V, Liu C. Systematic review and meta-analysis of clinical outcomes of descemet membrane endothelial keratoplasty versus descemet stripping endothelial keratoplasty/descemet stripping automated endothelial keratoplasty. Cornea. 2017;36(11):1437-43. 
12 Patel SV. Graft survival and endothelial outcomes in the new era of endothelial keratoplasty. Exp Eye Res. 2012;95(1):40-7.

13 Zhang $\mathrm{C}, \mathrm{Xu}$ J. Indications for penetrating keratoplasty in East China, 1994-2003. Graefes Arch Clin Exp Ophthalmol. 2005;243(10): 1005-9.

14 Tan JC, Holland SP, Dubord PJ, Moloney G, McCarthy M, Yeung SN. Evolving indications for and trends in keratoplasty in British Columbia, Canada, from 2002 to 2011: a 10-year review. Cornea. 2014;33(3):252-6.

15 Boimer C, Lee K, Sharpen L, Mashour RS, Slomovic AR. Evolving surgical techniques of and indications for corneal transplantation in Ontario from 2000 to 2009. Can J Ophthalmol. 2011;46(4):360-6.

16 Szaflik JP. Comparison of in vivo confocal microscopy of human cornea by white light scanning slit and laser scanning systems. Cornea. 2007;26(4):438-45.

17 Petroll WM, Robertson DM. In vivo confocal microscopy of the cornea: new developments in image acquisition, reconstruction, and analysis using the HRT-rostock corneal module. Ocul Surf. 2015;13(3):187-203.

18 Papaioannou L, Miligkos M, Papathanassiou M. Corneal collagen cross-linking for infectious keratitis: a systematic review and metaanalysis. Cornea. 2016;35(1):62-71.

19 Schaub F, Heindl LM, Enders P, Roters S, Bachmann BO, Cursiefen C. [Deep anterior lamellar keratoplasty: experiences and results of the first 100 consecutive DALK from the University Eye Hospital of Cologne]. Ophthalmologe. 2017;114(11):1019-26.
20 Guber I, Bergin C, Othenin-Girard P, Munier F, Majo F. 12-Year outcomes of microkeratome-assisted anterior lamellar therapeutic keratoplasty (ALTK) for disorders of the anterior part of the corneal stroma - a comparative review of adult and children. Klin Monbl Augenheilkd. 2018;235(4):404-8.

21 Melles GR, Eggink FA, Lander F, Pels E, Rietveld FJ, Beekhuis WH, et al. A surgical technique for posterior lamellar keratoplasty. Cornea. 1998;17(6):618-26.

22 Price DA, Kelley M, Price FW Jr, Price MO. Five-year graft survival of descemet membrane endothelial keratoplasty (EK) versus descemet stripping EK and the effect of donor sex matching. Ophthalmology. 2018;125(10): 1508-14.

23 Singh R, Gupta N, Vanathi M, Tandon R. Corneal transplantation in the modern era. Indian J Med Res. 2019;150(1):7-22.

24 Zhao S, Le Q, Yao W, Xu J. Indications and techniques of pediatric keratoplasty in Eastern China from 2008 to 2017. Cornea. 2019; 38(11):1370-6.

25 Le Q, Chauhan T, Yung M, Tseng CH, Deng SX. Outcomes of limbal stem cell transplant: a meta-analysis. JAMA Ophthalmol. 2020; 138(6):660-70.
26 Tominac Trcin M, Zdraveva E, Dolenec T, Vrgoč Zimić I, Bujić Mihica M, Batarilo I, et al. Poly( $\varepsilon$-caprolactone) titanium dioxide and cefuroxime antimicrobial scaffolds for cultivation of human limbal stem cells. Polymers. 2020;12(8): 1758 .

27 Jackson CJ, Myklebust Ernø IT, Ringstad H, Tønseth KA, Dartt DA, Utheim TP. Simple limbal epithelial transplantation: current status and future perspectives. Stem Cells Transl Med. 2020;9(3):316-27.

28 Nurković JS, Vojinović R, Dolićanin Z. Corneal stem cells as a source of regenerative cellbased therapy. Stem Cells Int. 2020;2020: 8813447.

29 Kinoshita S, Koizumi N, Ueno M, Okumura $\mathrm{N}$, Imai $\mathrm{K}$, Tanaka $\mathrm{H}$, et al. Injection of cultured cells with a ROCK inhibitor for bullous keratopathy. N Engl J Med. 2018;378(11): 995-1003.

30 Bakhshandeh H, Atyabi F, Soleimani M, Taherzadeh ES, Shahhoseini S, Cohan RA. Biocompatibility improvement of artificial cornea using chitosan-dextran nanoparticles containing bioactive macromolecules obtained from human amniotic membrane. Int J Biol Macromol. 2021;169:492-9.

31 Zheng J, Huang X, Zhang Y, Wang Y, Qin Q, Lin L, et al. Short-term results of acellular porcine corneal stroma keratoplasty for herpes simplex keratitis. Xenotransplantation. 2019; 26(4):e12509. 